\title{
Chemical Structure of Nitrogen-Doped Graphene with Single Platinum Atoms and Atomic Clusters as a Platform for the PEMFC Electrode
}

\author{
Samantha Stambula, ${ }^{\dagger}$ Nicolas Gauquelin, ${ }^{\dagger}$ Matthieu Bugnet, ${ }^{\dagger}$ Sandeep Gorantla, ${ }^{\dagger, \S}$ Stuart Turner, ${ }^{\dagger, \|}$
} Shuhui Sun, ${ }^{\ddagger} \perp$ Jian Liu, ${ }^{\ddagger}$ Gaixia Zhang, ${ }^{\ddagger}, \perp$ Xueliang Sun, ${ }^{\ddagger}$ and Gianluigi A. Botton*, ${ }^{\dagger}$

${ }^{\dagger}$ Department of Materials Science and Engineering, McMaster University, 1280 Main Street West, Hamilton, Ontario, L8S 4L8, Canada

${ }^{\ddagger}$ Department of Materials and Mechanical Engineering, Western University, 1151 Richmond Street North, London, Ontario, N6A 5B9, Canada

\section{Supporting Information}

\begin{abstract}
A platform for producing stabilized $\mathrm{Pt}$ atoms and clusters through the combination of an N-doped graphene support and atomic layer deposition (ALD) for the Pt catalysts was investigated using transmission electron microscopy (TEM) and scanning transmission electron microscopy (STEM). It was determined, using imaging and spectroscopy techniques, that a wide range of $\mathrm{N}$-dopant types entered the graphene lattice through covalent bonds without largely damaging its structure. Additionally and most notably, Pt atoms and atomic clusters formed in the absence of nanoparticles. This work provides a new strategy for experimentally producing stable atomic and subnanometer cluster catalysts, which can greatly assist the proton exchange membrane fuel cell (PEMFC) development by producing the ultimate surface area to volume ratio catalyst.
\end{abstract}

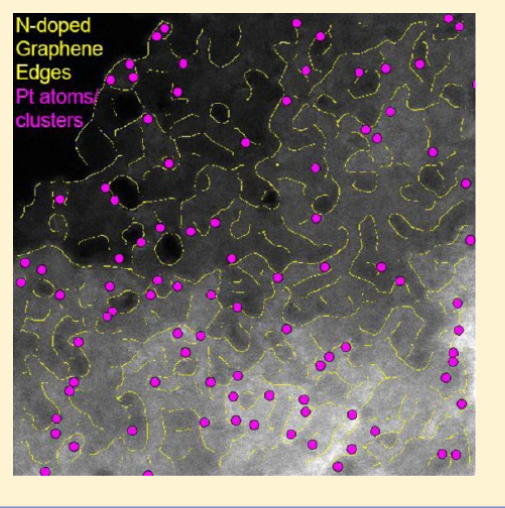

\section{INTRODUCTION}

Alternative energy sources have become a key research interest in the quest to address environmental degradation and the depletion of nonrenewable fuel sources. As a promising candidate for environmentally benign electric power generation technology, proton-exchange membrane fuel cells (PEMFCs) have drawn a great deal of attention thanks to their fast startup, ${ }^{1}$ high power density, ${ }^{1}$ and low or zero emissions. ${ }^{2}$ Currently, platinum $(\mathrm{Pt})$ has proven to perform the oxygen reduction reaction (ORR) as a homocatalyst at the cathode of the PEMFC most efficiently; ${ }^{3}$ however, Pt-based electrocatalysts and their associated electrodes can be the largest expense during the production of the PEMFC. ${ }^{4}$ Downsizing Pt catalysts to subnanometer clusters could significantly increase catalytic activity by enhancing the surface area to volume ratio, resulting in additional active sites and a decreased overall cost by reducing the total mass of $\mathrm{Pt}$ per electrode. Other limitations plaguing the efficiency and mass-production of the PEMFC include catalyst degradation through operation, ${ }^{5}$ nonuniform $\mathrm{Pt}$ distribution, ${ }^{6}$ and low-surface area electrode supports. ${ }^{5}$

Conventionally, C black supports with Pt nanoparticles are used in PEMFCs. Recently, graphene supports have been investigated, as this remarkable two-dimensional material exhibits high electrical conductivity, ${ }^{7}$ mechanical robustness, ${ }^{8}$ and a high surface area. ${ }^{7}$ The intrinsic nature of the strong $\mathrm{sp}^{2}$ chemical bonds composing the graphene lattice does not readily permit the chemisorption of $\mathrm{Pt}$ on the graphene surface, thus the Pt atoms migrate to edge locations where free dangling bonds are available; ${ }^{9}$ unfortunately, this high mobility results in a poor catalyst distribution and possibly enhanced particle agglomeration. ${ }^{6}$

Functionalization is a common method used to create binding sites on the graphene lattice through the introduction of dopant atoms. ${ }^{10,11} \mathrm{~A}$ wealth of knowledge is available in the literature on various types of nitrogen-dopants ( $\mathrm{N}$-dopants) in $\mathrm{N}$-doped graphene, consisting of amino-, pyridinic-, pyrrolic-, and graphitic-dopants. ${ }^{12-14}$ It has been experimentally reported that the $\mathrm{N}$-doping increases the efficiency of the PEMFC in comparison to conventional supports, as it increases the dispersion of the $\mathrm{Pt}$ catalyst, ${ }^{12}$ prevents $\mathrm{Pt}$ agglomeration, ${ }^{15}$ and participates in the ORR as active sites for catalysis. ${ }^{16-18}$ The significance of each type of N-dopant on the ORR is controversial in the scientific literature, as direct observation of the ORR has not been completed with current experimental techniques. Kim et al. ${ }^{19}$ reference a series of publications illustrating the disagreement in the literature regarding the origin of the active source for ORR between graphitic-N and pyridinic-N. Through their own calculations and ORR reaction scheme, they determined that the debate on the active site may be due to the transformation of a graphitic-type dopant into a

Received: September 7, 2013

Revised: January 16, 2014

Published: February 12, 2014 
pyridinic-type dopant during the ORR process. It has also been proposed, through simulations, that graphitic-type ${ }^{15}$ and pyrrolic-type $^{20}$ doping induces a positive charge on the adjacent $\mathrm{C}$ atom due to the increased electronegativity of the $\mathrm{N}$ atom, resulting in the $\mathrm{C}$ atom acting as a potential molecular adsorption site. Through DFT calculations, $\mathrm{Ni}$ et al. ${ }^{21}$ demonstrated that graphitic-type doping offers the lowest overall energy barrier for the dissociation of $\mathrm{O}_{2}$, thus suggesting that the graphitic-dopant is the most active for the ORR.

A method to increase the surface area to volume ratio of the $\mathrm{Pt}$ catalyst is through tuning the deposition process. Pt is commonly deposited through solution synthesis, electrodeposition, and physical sputtering; ${ }^{22}$ however, the use of atomic layer deposition (ALD) has been shown to create particles with an average size of 2 to $5 \mathrm{~nm},{ }^{23-25}$ and in particular cases ultrasmall nanoparticles $(<1 \mathrm{~nm})^{11}$ and single atoms $^{25}$ have been produced. The effect of $\mathrm{Pt}$ atoms and clusters on ORR is also debated in scientific literature, as the consistent production of Pt clusters is hardly achievable, and substrate effects need to be considered. Toyoda et al. ${ }^{26}$ demonstrated through calculations that chemisorbed small $\mathrm{Pt}$ clusters (less than 4 atoms) on defective graphene results in a larger d-band separation from the Fermi energy and can lead to greater ORR efficiency. Further, additional calculations by Zhou et al. ${ }^{27}$ showed that small $\mathrm{Pt}$ clusters $\left(\mathrm{Pt}_{2}\right)$ have the largest average $\mathrm{H}_{2}$ dissociative chemisorption energy and $\mathrm{H}$ atom desorption energy, which suggests that the formation of very small clusters, consisting of few $\mathrm{Pt}$ atoms, will drastically increase the catalytic activity of the anode. As suggested through calculations, ${ }^{27,26}$ the use of $\mathrm{Pt}$ atoms and clusters should exhibit an enhanced catalytic efficiency compared to conventional Pt nanoparticles on C black, due to the increased rate of the $\mathrm{H}$ oxidation and the ORR.

Although studies have shown successful deposition of the Pt atoms and clusters, they lack experimental evidence of the correlation of the $\mathrm{Pt}$ structure and location with respect to the structure of the graphene nanosheets and $\mathrm{N}$-dopant sites. This is crucial for understanding and optimizing the production of $\mathrm{Pt}$ atoms and clusters in the absence of nanoparticles. The effect of the graphene structure, specific N-dopants, and the Pt size (atomic to subnanometer clusters) on the catalytic activity can only be understood and optimized through detailed characterization of the material's structure at the atomic scale. Through the use of transmission electron microscopy (TEM), the Ndoped graphene and Pt catalyst are here fully characterized. We show that the combination of $\mathrm{N}$-doped graphene and ALD Pt generates clusters and single atoms, resulting in a catalyst with a high surface area to volume ratio for the PEMFC. Specifically, high-resolution TEM (HRTEM) and high-angle annular darkfield (HAADF) imaging were utilized to determine the structural information of the graphene lattice and the $\mathrm{Pt}$ distribution. Electron diffraction and electron-energy loss spectroscopy (EELS) were used to investigate the quality of the $\mathrm{N}$-doped graphene, local variation of $\mathrm{N}$ content, and the site preference of $\mathrm{N}$ in the lattice. These techniques ultimately provide a full understanding of the material structure, thus deeming them as invaluable tools and techniques for material optimization.

\section{EXPERIMENTAL SECTION}

2.1. Material Preparation. 2.1.1. Graphene and N-Doped Graphene. Graphene nanosheets were first synthesized via a modified Hummers method, ${ }^{28,29}$ which involves graphite oxidation, thermal exfoliation, and chemical reduction. In detail, natural graphite powder (1 g, 99.99\%, Sigma-Aldrich) was first stirred in concentrated sulphuric acid $\left(\mathrm{H}_{2} \mathrm{SO}_{4}, 23 \mathrm{~mL}\right)$, followed by an addition of sodium nitrate $\left(\mathrm{NaNO}_{3}, 0.5 \mathrm{~g}\right)$ at room temperature. The stirring persisted for $16 \mathrm{~h}$, where the mixture was then cooled to $0{ }^{\circ} \mathrm{C}$. Potassium permanganate $\left(\mathrm{K}_{2} \mathrm{MnO}_{4}, 3 \mathrm{~g}\right)$ was then added to the solution. After $2 \mathrm{~h}$, the solution formed a green slurry around a temperature of $35^{\circ} \mathrm{C}$, which was stirred for another $3 \mathrm{~h}$. Subsequently, $46 \mathrm{~mL}$ of deionized water $\left(\mathrm{H}_{2} \mathrm{O}\right)$ was slowly added into the slurry at a temperature of approximately $98{ }^{\circ} \mathrm{C}$. The suspension temperature was maintained for $30 \mathrm{~min}$ before it was further diluted with another addition of $\mathrm{H}_{2} \mathrm{O}$ and hydrogen peroxide $\left(\mathrm{H}_{2} \mathrm{O}_{2}\right.$, $140 \mathrm{~mL}$ ). The suspension was subsequently filtered and washed until it reached a neutral $\mathrm{pH}$, where it was then dried in a vacuum oven at $60{ }^{\circ} \mathrm{C}$ to obtain graphite oxide (GO). To transform the GO to graphene, the as-synthesized GO was heated around $1050{ }^{\circ} \mathrm{C}$ in an $\mathrm{Ar}$ atmosphere for $30 \mathrm{~s}$ in a tube furnace. $\mathrm{N}$-doped graphene was further obtained by heating the graphene powder under high purity ammonia/Ar at $900{ }^{\circ} \mathrm{C} .{ }^{30}$

For the purpose of being used as a reference material, a commercially available TEM grid containing graphene was purchased from Graphene Supermarket (product information available at https://graphene-supermarket.com/). The graphene was produced through the chemical vapor deposition (CVD) method and consisted of 1 to 6 layers. ${ }^{31}$ The supplier provided directly transferred graphene on a 300 mesh Cu TEM grid with an amorphous lacey $\mathrm{C}$ support. ${ }^{31}$

2.1.2. ALD of Pt on N-Doped Graphene. Pt was deposited on N-doped graphene by ALD (Savannah 100, Cambridge Nanotechnology Inc., USA) using (methylcyclopentadienyl)trimethylplatinum ( $\mathrm{MeCpPtMe}_{3}$, Aldrich, purity 98\%) and $\mathrm{O}_{2}$ (99.999\%) as precursors, and $\mathrm{N}_{2}$ (99.9995\%) as the purge gas. The apparatus used for ALD consists of a wall reactor with an outlet leading to a vacuum pump, which also prevents air from entering the system. The inlet was connected to a system of valves that controlled the delivery of the purge gas and precursors. To increase the heat transfer from the stage to the $\mathrm{N}$-doped graphene, hot wall conditions were replicated by placing the $\mathrm{N}$-doped graphene powder inside a machined stainless steel container with a perforated $\mathrm{Al}$ lid. The container for the $\mathrm{N}$-doped graphene was then placed inside the reactor directly on the heated stage. The wall and stage temperatures of the reactor were kept at 150 and $250{ }^{\circ} \mathrm{C}$, respectively. The container for $\mathrm{MeCpPtMe}_{3}$ was kept at $65{ }^{\circ} \mathrm{C}$, providing a steady state flux of $\mathrm{MeCpPtMe}_{3}$ to the reactor. ${ }^{24}$ Each ALD cycle consisted of a $1 \mathrm{~s} \mathrm{MeCpPtMe}_{3}$ pulse, followed by a $20 \mathrm{~s}$ $\mathrm{N}_{2}$ purge, and a subsequent $5 \mathrm{~s} \mathrm{O}_{2}$ pulse.

2.2. Microscopy. The $\mathrm{N}$-doped graphene powders were transferred to a 200-mesh copper grid with a lacey amorphous C support via the dry-press method. The samples were examined with an $80 \mathrm{kV}$ electron source to reduce knock-on damage to the graphene. ${ }^{32,33}$ In addition, the high electrical conductivity of the $\mathrm{N}$-doped graphene inherently reduces the possibility of ionization damage to the sample. ${ }^{34}$ HRTEM and HAADF experiments were performed with an FEI Titan 80300 Cubed TEM equipped with a monochromator, hexapolebased aberration correctors (Corrected Electron Optical Systems $\mathrm{GmbH}$ ) for the image and probe lenses, and a high brightness field emission gun (XFEG). For HRTEM, the spherical-aberration correction of the objective lens was set to a negative $C_{s}$ configuration $^{34}$ with a monochromated beam. Similarly, HAADF-STEM was performed with the aberration- 

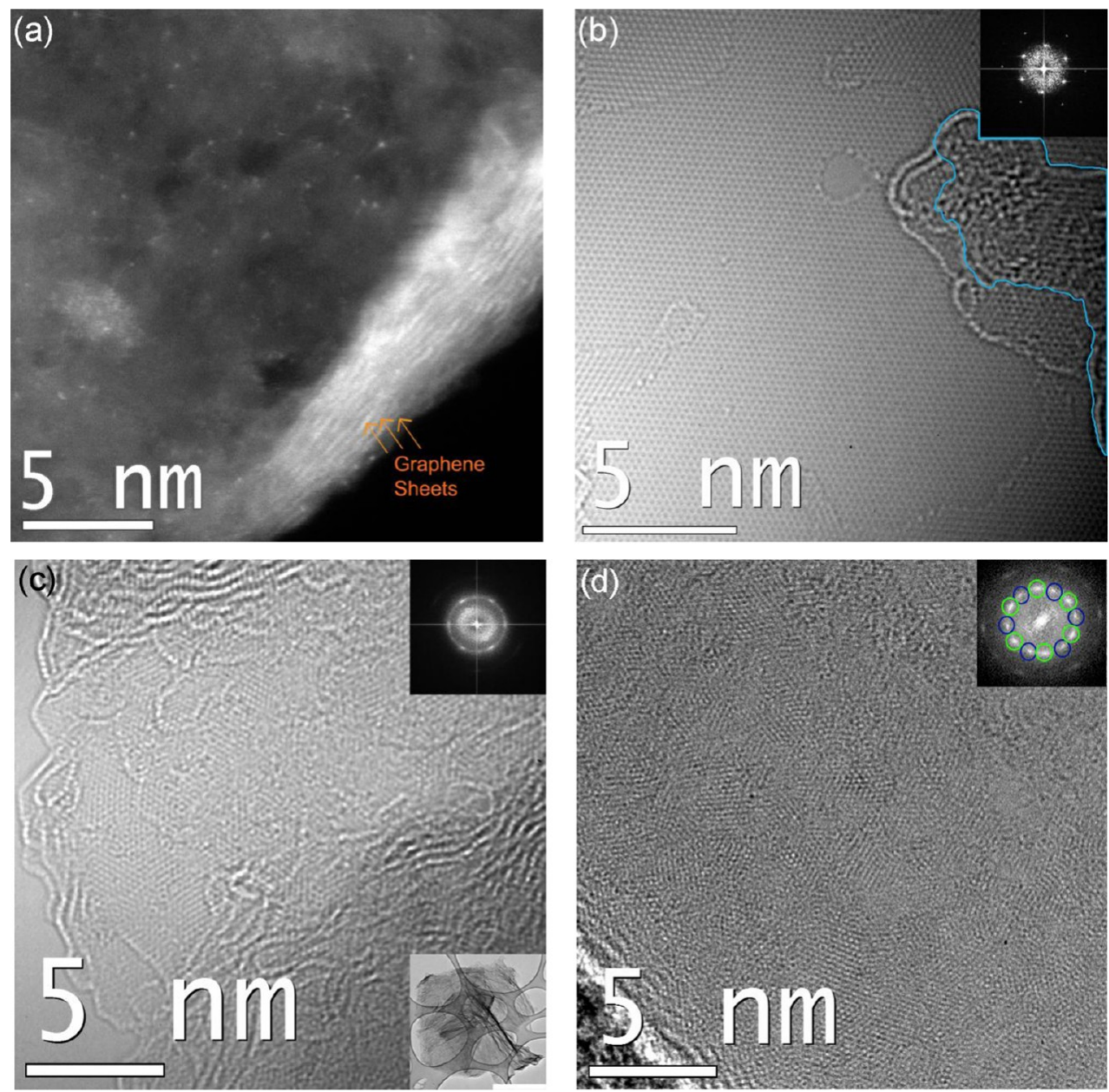

Figure 1. (a) HAADF image after $150 \mathrm{Pt}$ ALD cycles on N-doped graphene. The edges of the graphene sheets are labeled in orange, indicating that the thermally exfoliated graphene does not consist of single sheets. (b) HRTEM micrographs were acquired from commercially obtained graphene, (c) the edge of an N-doped graphene sheet $(\mathrm{Cs}=-40 \mu \mathrm{m})$, and (d) the bulk area of N-doped graphene after 50 ALD cycles $(\mathrm{Cs}=-15 \mu \mathrm{m})$. The commercial graphene contains floating hydrocarbons encircled in blue. The lower inset in panel c shows a general overview of the N-doped graphene sheets (scale bar $1 \mu \mathrm{m}$ ). Fourier transform diffractograms are displayed in top insets of $\mathrm{b}$, $\mathrm{c}$, and $\mathrm{d}$ and illustrate the characteristic hexagonal structure of graphene. The 12 elongated diffraction spots highlighted with circles (green and blue) in (d) are a result of two main grain orientations, while the broadening of the diffraction spots can be attributed to stacking misorientations, defects in the graphene lattice, and lattice folding within the field of analysis. The top inset in $(\mathrm{d})$ suggests that the short-range order of the hexagonal lattice is maintained.

corrector tuned to minimize spherical aberration in the probeforming lens.

EELS and nanoprobe diffraction experiments were carried out with an FEI 80-300 Cryo-Twin TEM equipped with a monochromator, and a Schottky field emission gun (SFEG). Specifically, the energy loss near edge structure (ELNES) from the EEL spectra was extracted to understand the bonding environment of the $\mathrm{C}, \mathrm{N}$, and $\mathrm{O}$ atoms. The EELS acquisition for the $\mathrm{N}-\mathrm{K}$ edge was performed in STEM mode with the spectrum imaging technique implemented by the GATAN Digital Micrograph software, using the monochromator to achieve an energy resolution of $0.08 \mathrm{eV}$ as measured from the full width at half-maximum of the zero-loss peak. The low $\mathrm{N}$ concentration in the graphene and small cross-section of the $\mathrm{N}-\mathrm{K}$ edge increases the difficulty in collecting the ELNES. ${ }^{35}$ Long acquisition times ranging from 3.0 to $4.0 \mathrm{~s} /$ pixel were utilized to acquire the $\mathrm{N}-\mathrm{K}$ edge with a high signal-to-noise ratio to ensure the fine structure corresponding to each $\mathrm{N}$ dopant was resolved. A dispersion of $0.1 \mathrm{eV} /$ pixel was used for EELS acquisition of the $\mathrm{C}-\mathrm{K}$ and the $\mathrm{N}-\mathrm{K}$ edges with the areas carefully monitored before and after acquisition of the spectra to ensure contamination from surface hydrocarbons did not influence the fine structures. The EEL spectra containing the $\mathrm{O}-\mathrm{K}$ edge were acquired on the FEI Titan 80-300 Cubed with a dispersion of $0.2 \mathrm{eV} /$ pixel for simultaneous acquisition of $\mathrm{C}-\mathrm{K}, \mathrm{N}-\mathrm{K}$, and $\mathrm{O}-\mathrm{K}$ edges. The background of the EEL spectra were removed using a power-law fit. ${ }^{36}$ Lastly, the energy dispersive $\mathrm{x}$-ray spectroscopy (EDXS) data was acquired with an FEI Tecnai-Osiris microscope equipped with a Super-EDX spectrometer and a single aligned excitation voltage of $200 \mathrm{kV}$.

The quantification and processing of the HAADF images to determine the location of $\mathrm{Pt}$ with respect to the graphene edges were carried out as follows. A band-pass filter was first applied to the HAADF images in order to determine the $\mathrm{Pt}$ atom locations. Images were then smoothed with a Gaussian blur, and the local gradients (Sobel filter) were examined to determine the position of the edges of the graphene sheets. Lastly, the Pt atoms and graphene edge outlines were then superimposed on the original image.

Quantification of the sample composition was determined using EELS edges. The concentration of the $\mathrm{N}$ and $\mathrm{O}$ were calculated using the quantification routine in the GATAN 

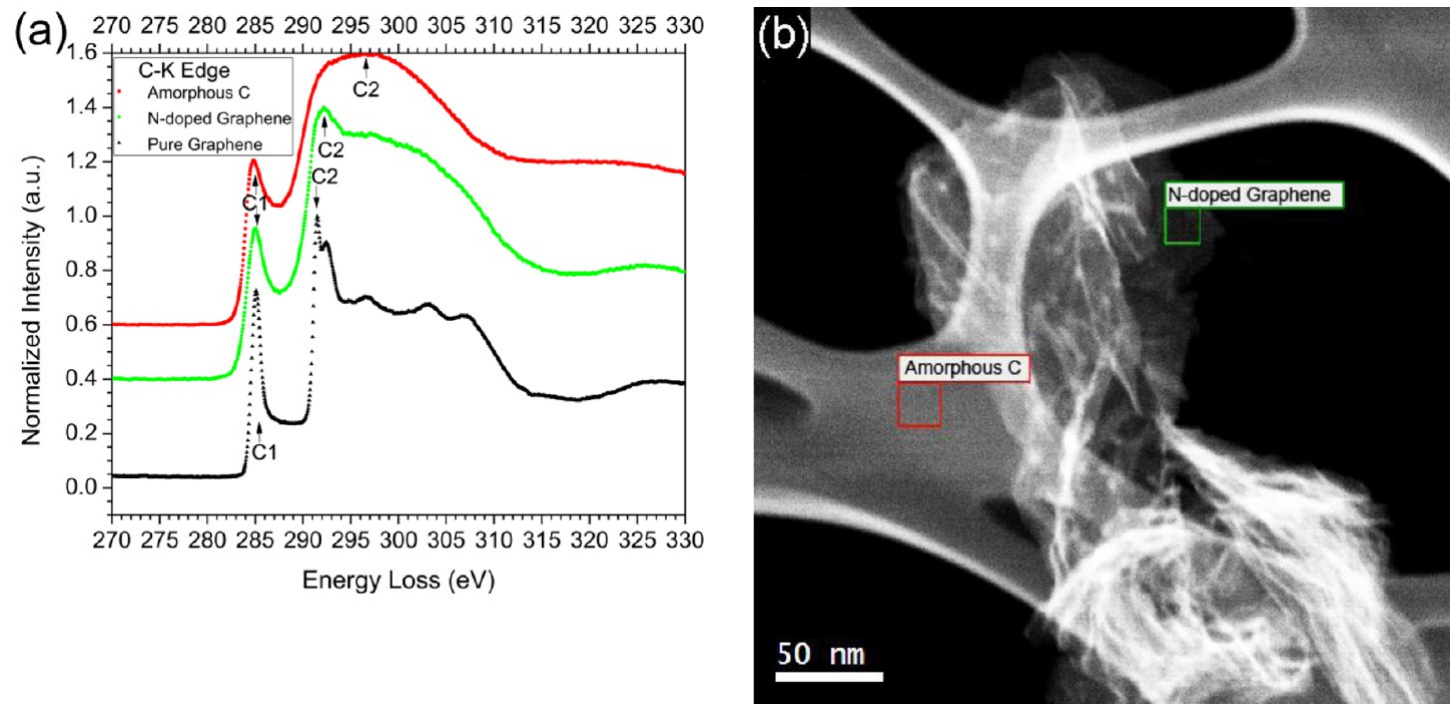

Figure 2. (a) C-K edge ELNES from amorphous C (red), N-doped graphene with 50 ALD Pt cycles (green), and pure graphene (black). The C-K edge $\pi^{*}$ and $\sigma^{*}$ peaks are labeled as $\mathrm{C} 1$ and $\mathrm{C} 2$, respectively. The $\mathrm{N}$-doped graphene and amorphous $\mathrm{C}$ EEL spectra in panel (a) were acquired from the corresponding colored outlined areas in panel (b), and the EEL spectrum of pure graphene in panel (a) was acquired from a standard commercial reference sample.

Digital Micrograph software with the Hartree-Slater crosssection model and the extraction of the signals of the $\mathrm{N}-\mathrm{K}$ and $\mathrm{O}-\mathrm{K}$ edges relative to the $\mathrm{C}-\mathrm{K}$ edge.

\section{RESULTS AND DISCUSSION}

3.1. Graphene. Graphene obtained from thermal exfoliation of GO is susceptible to incomplete exfoliation at reduced temperature and time, thus producing few-layer graphene (FLG) as observed by the fringes induced by folding in Figure 1a (orange arrows indicating fringe locations) and the overview of the N-doped FLG sheet in the bottom inset of Figure 1c. The defects inflicted on the graphene lattice by the thermal exfoliation $^{37}$ and the incorporation of $\mathrm{N}$-dopants can be visualized with HRTEM images in single-layer graphene, as illustrated by Gómez-Navarro et al. ${ }^{38}$ and Meyer et al. ${ }^{39,40}$ For the use of qualitative analysis and comparison, Figure $1 \mathrm{~b}$ of commercially produced CVD graphene illustrates the characteristic hexagonal lattice of graphene with slight contamination from hydrocarbons floating on the surface as islands (encircled in blue in Figure $1 \mathrm{~b}$ ). While the CVD-grown graphene is not defect-free, in qualitative comparison, the $\mathrm{N}$-doped graphene is highly defective on the long-range, as suggested by the multitude of grain boundaries and layers from the edges of the $\mathrm{N}$-doped graphene sheets in the HRTEM image (Figure 1c) with confirmation from the computed diffractograms (Figure $1 \mathrm{c}, \mathrm{d}$, top inset). In the short-range, the complex hexagonal lattice of the N-doped FLG is visible in the thin regions of the $\mathrm{N}$-doped graphene edge (Figure 1c), where the computed diffractogram of the bulk area image (Figure 1d, top inset) confirms the presence of the hexagonal lattice of graphene. Two sets of hexagonal elongated spots in the diffractogram (encircled in blue and green) indicate that the $\mathrm{N}$ doped graphene in this area contains two main grain orientations. Anisotropic broadening of the diffraction spots can be observed in the diffractograms originating from the $\mathrm{N}$ doped graphene, while distinct diffraction spots are observed for the CVD-grown graphene. The angular broadening is attributed to multiple low- and high-angle misorientations, likely due to the defects present in the lattice, lattice folding, and the presence of misoriented sheets within and between graphene layers. ${ }^{41,42}$ Such information is also confirmed by selected area diffraction from a different area of the sample (see Supporting Information, Figure S1). Most importantly, the obvious hexagonal arrangement of the computed diffraction pattern reveals that the short-range graphene structure is maintained after $\mathrm{N}$-doping.

The nature of the local environment of the $\mathrm{C}$ atoms in the FLG was studied through a comparison of the $\mathrm{C}-\mathrm{K}$ edge ELNES of the $\mathrm{N}$-doped graphene (Figure 2a, green plot) to the amorphous $\mathrm{C}$ support on the TEM grid (Figure 2a, red plot) and commercial graphene (Figure 2a, black plot). While a first inspection reveals similarities in the overall shape of the three spectra, the sharp $\pi^{*}$ peak (labeled as $\mathrm{C} 1$ ) and $\sigma^{*}$ peak (C2) of the $\mathrm{C}-\mathrm{K}$ edge of the $\mathrm{N}$-doped graphene bear strong similarities to the pure graphene EEL spectrum, as opposed to the weak $\pi^{*}$ and broad $\sigma^{*}$ peak of the amorphous $\mathrm{C}$ where $\mathrm{C}$ is in the $\mathrm{sp}^{2}$ configuration. It is clear that the excitonic peak at approximately $292 \mathrm{eV}$ in $\mathrm{C} 2$ is present in both the pure graphene and the $\mathrm{N}$-doped graphene, while it is absent in the amorphous $\mathrm{C}-\mathrm{K}$ edge. This suggests that defects introduced from the $\mathrm{N}$-doping process do not affect the very short-range order (i.e., the $\mathrm{C}$ is still mostly in trigonal coordination) and the hybridization of the $\mathrm{C}$ atoms in a detectable way, which is likely due to the small concentration of dopants. The slight broadening of the $\sigma^{*}$ peak $(\mathrm{C} 2)$ of the $\mathrm{N}$-doped graphene in comparison to the commercial graphene, indicates longer-range distortions and is consistent with the disorder observed from the computed diffractograms in Figure 1d. In particular, the loss of some fine-structure features occurring in the $\mathrm{C}-\mathrm{K}$ edge after the excitonic peak (e.g., at 296, 302, and $306 \mathrm{eV}$ ) and a broadening of the $\pi^{*}$ peak $(\mathrm{C} 1)$ in the $\mathrm{N}$-doped graphene EEL spectrum, as compared to the reference graphene, suggests the highly defective nature of the $\mathrm{N}$-doped graphene.

Defects in the structure of the $\mathrm{N}$-doped graphene lattice can be attributed to the graphene production method and the $\mathrm{N}$ dopants. Direct visualization of the $\mathrm{N}$-dopant atoms is not realistically possible due to the multilayered nature of the sample and the similarity in electron scattering of the $\mathrm{C}$ and $\mathrm{N}$ 
atoms that gives rise to contrast in imaging techniques in TEM. ${ }^{12}$ Consequently, the site location of specific dopants in images such as Figure 1c,d cannot be taken further in our work. An additional defect source is due to the incorporation of $\mathrm{O}$ species from the incomplete reduction of the GO, resulting in hydroxyl, epoxy, carbonyl, and carboxyl groups on the surface of the graphene lattice. ${ }^{43,44}$ These moieties can give rise to the broader onset of the $\sigma^{*}$ peak $(\mathrm{C} 1)$ of the $\mathrm{N}$-doped graphene edge in Figure 2a, but no single peak attributed to any of the $\mathrm{O}$ groups appears to dominate this well resolved region. ${ }^{45,46} \mathrm{O}$ containing defects contribute to the structural defects observed in Figure 1d, as EELS analysis of the O-K edge indicates a 9.1 atomic \% O within the sample (see Supporting Information, Figure S2). This suggests that the defects in the graphene arise from the thermal exfoliation production method, the incomplete reduction, and the $\mathrm{N}$-species; however, as suggested by the various characterization techniques, the overall shortrange graphene quality is preserved.

3.2. Nitrogen Doping. Various experimental results report the incorporation of specific $\mathrm{N}$-species in the graphene lattice through X-ray absorption near edge structures (XANES) of the $\mathrm{N}-\mathrm{K}$ edge, ${ }^{12,47-49}$ X-ray photoemission spectroscopy (XPS) binding energies, ${ }^{14,50}$ and DFT calculations. ${ }^{51}$ The N-dopant atoms were detected here with EELS through examination of the $\mathrm{N}-\mathrm{K}$ edge, as shown in Figure 3. Through quantification of the spectra, relative to the $\mathrm{C}-\mathrm{K}$ edge, the local concentration of the $\mathrm{N}$ atoms in different areas was determined (Table 1). The noise associated with the $\mathrm{N}-\mathrm{K}$ edge is a result of the low

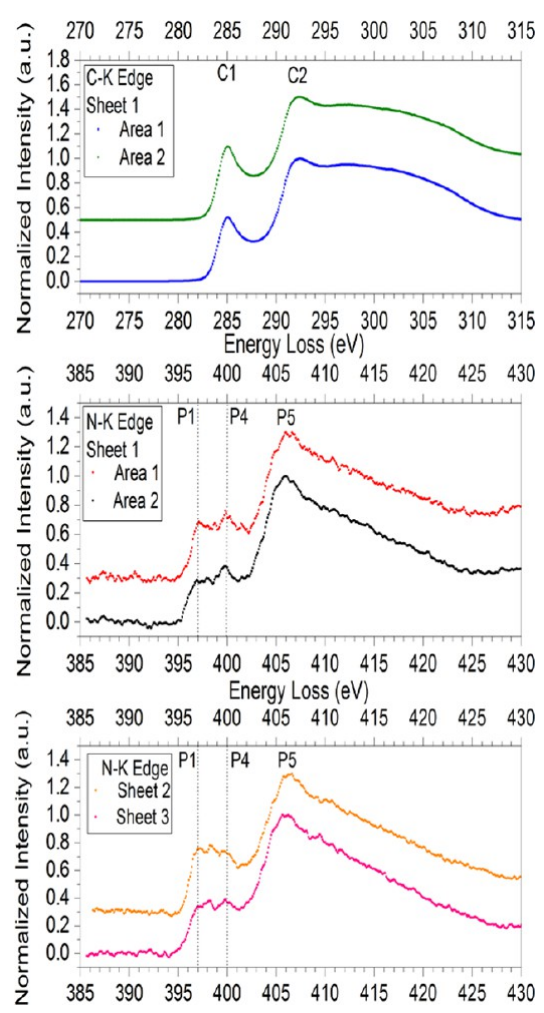

Figure 3. Normalized EEL spectra of $\mathrm{C}-\mathrm{K}$ and $\mathrm{N}-\mathrm{K}$ edges acquired from three $\mathrm{N}$-doped graphene sheets with 50 ALD Pt cycles and two separate areas on sheet 1 . The $\pi^{*}$ and $\sigma^{*}$ components of the $\mathrm{C}-\mathrm{K}$ edge are labeled as $\mathrm{C} 1$ and $\mathrm{C} 2$, respectively. Furthermore, the $\mathrm{N}-\mathrm{K}$ edge is also divided by the $\pi^{*}(\mathrm{P} 1-\mathrm{P} 4)$ and $\sigma^{*}(\mathrm{P} 5)$ regions, where $\mathrm{P} 1$ to $\mathrm{P} 4$ are attributed to the individual $\mathrm{N}$-dopants of pyridinic-, amino-, pyrrolic-, and graphitic-type, respectively.
Table 1. Atomic N Fraction Deduced from Quantification of the EELS N-K Edges in Figure 3

$\begin{array}{cc}\text { graphene sheet number (area number) } & \text { atomic percent } \mathrm{N} \\ 1(1) & 7.3 \pm 1.0 \\ 1(2) & 6.6 \pm 0.9 \\ 2 & 6.9 \pm 0.9 \\ 3 & 6.0 \pm 0.8\end{array}$

atomic $\mathrm{N}$ concentration, as reported in Table 1. In addition, from inspection of the near edge structure, the presence of strong features in the N-K edge from 397 to $400 \mathrm{eV}$ associated with $\pi$ hybridization (P1-P4), and the feature at $405 \mathrm{eV}$ (P5) associated with $\sigma$ hybridization can be observed. Each Ndopant species has a specific bonding environment that represents a characteristic peak in the $\mathrm{N}-\mathrm{K}$ edge fine-structure appearing in the energy range from 397 to $400 \mathrm{eV}$, identified with increasing energy as pyridinic (P1), amino (P2), pyrrolic (P3), and graphitic (P4) (recognized in Figure 3). ${ }^{12,14,47-49,51}$ Unlike Nicholls et al., ${ }^{35}$ an extra well-resolved feature attributed to the $\mathrm{N}$ atoms is not observed in the $\mathrm{C}-\mathrm{K}$ edge, as the $\mathrm{EEL}$ spectra were averaged over hundreds of nanometers in effort to extract the $\mathrm{N}-\mathrm{K}$ edge rather than acquiring atomically resolved spectra from surrounding $\mathrm{C}$ atoms.

Although we cannot be quantitative in the absolute $\mathrm{N}$-species concentration because reference spectra of individual species are not available, changes in the relative contributions of $\mathrm{N}$ atoms in various bonding environments can be shown. It is possible to infer, from the $\mathrm{N}-\mathrm{K}$ near edge structures (Figure 3 ) that there are local variations in the relative proportions of different $\mathrm{N}$-species between $\mathrm{N}$-doped FLG sheets and even possibly within a single sheet, as the relative intensity of the P1 to $\mathrm{P} 4$ peaks (hence the weight of pyridinic, amino, pyrrolic, and graphitic moieties) vary locally. The $\mathrm{N}$ concentration, as determined by EELS analysis, is within the same compositional range between each examined sheet in Figure 3 (Table1); however, local variations in the distribution and concentration of the individual $\mathrm{N}$-species exist among the graphene sheets. This is specifically evident through the presence of three peaks in sheet 2 (P1, P2, and P4), whereas only two peaks (P1, and $\mathrm{P} 4)$ are observed in the other $\mathrm{N}$-doped graphene sheets. P3 is not visible in the $\pi^{*}$ region due the requirement that the pyridinic defect must be present prior to doping and a possible overlap from the strong P4 peak.

From spatially resolved EELS measurements of several FLG flakes, it is also clear that $\mathrm{N}$ is not present in every sheet or its concentration is below the practical detection limit of EELS of approximately $0.5 \%$ in our experimental conditions. It can be suggested that the variation in the relative overall concentration between sheets may be an effect of the location of the sheet within the bulk powder during the doping process. The ammonia gas would likely be more readily available to sheets directly exposed to the flow of the gas rather than within regions of the batch powder where doping would be limited by diffusion. N-doped graphene sheets in Table 1 were likely located near the surface of the batch powder during the doping process, while the sheets without a detectable $\mathrm{N}-\mathrm{K}$ edge were likely located deeper within the powder.

The $\mathrm{N}-\mathrm{K}$ near edge structures of the electrode material presented here suggests that each of the nondefect induced dopant sites (pyridinic (P1), amino (P2), and graphitic (P4)) are present in the samples under consideration. It is thus possible to infer that an enhanced ORR activity is expected 

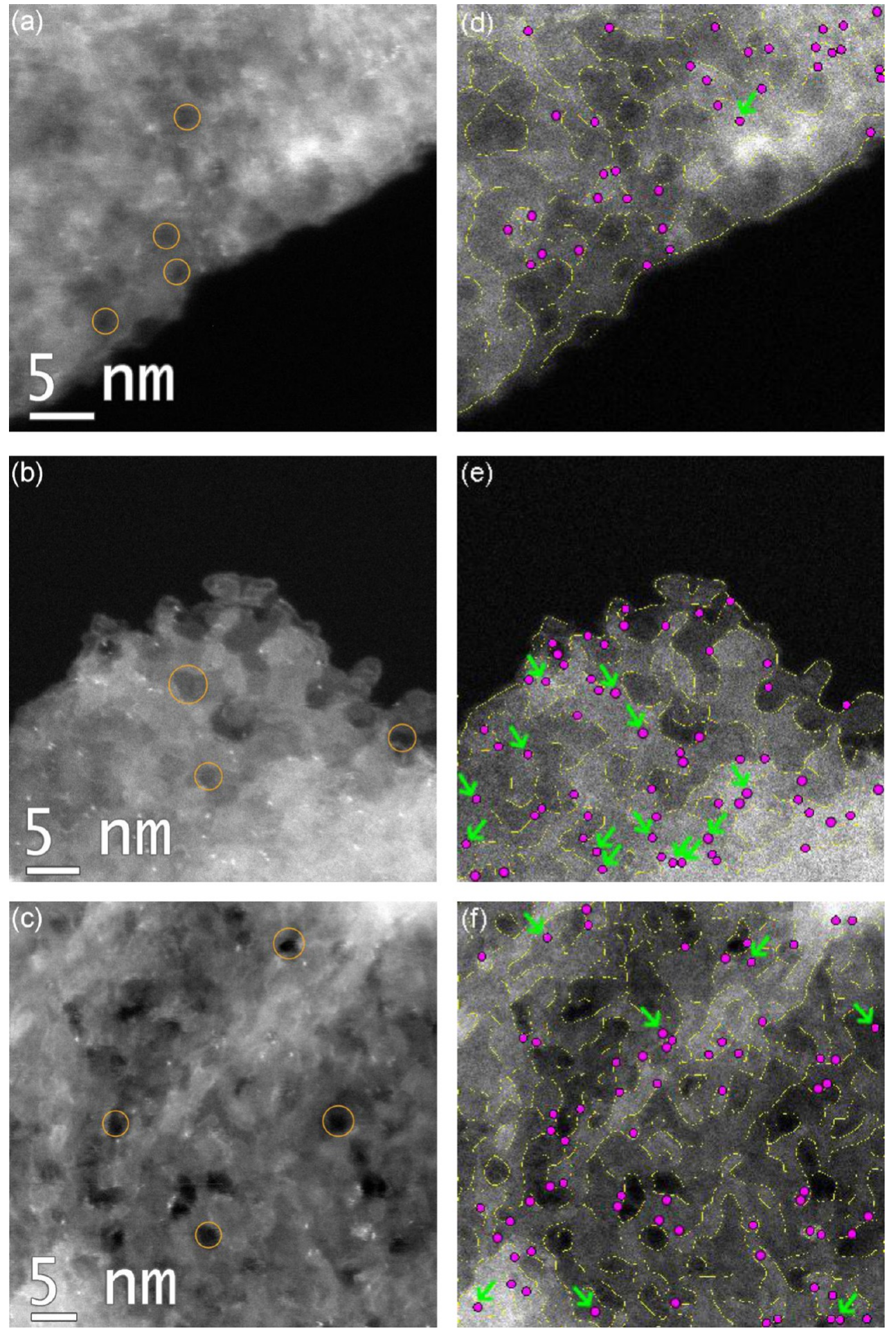

Figure 4. Raw (left) and processed (right) HAADF images of (a,d) 50, (b,e) 100, and (c,f) 150 ALD Pt cycles on N-doped graphene, respectively. The orange circles in the raw images locate the specific areas with fewer layers in the graphene lattice from the destructive thermal exfoliation process. The processed images outline the edges of the graphene nanosheets with yellow lines, and the Pt atoms and clusters are distinguished with pink dots. These are simply overlaid on the original raw image. Green arrows highlight atoms that are not located on the edges of the graphene sheets. Specific details of the processed images can be found in the Experimental Section.

when these materials are tested for their electrochemical performance. Nevertheless, the N-dopants are not homogenously distributed across the graphene sheets or within the FLG sample, thus resulting in local variations of ORR. Our results also suggest that local measurements such as the ones reported in the present work, rather than average measure- ments with broad-beam methods, need to be carried out in order to optimize the synthesis and thus ensure full utilization of the electrode support for the ORR.

3.3. Platinum Catalyst. The $\mathrm{Pt}$ atoms and clusters deposited on $\mathrm{N}$-doped graphene through ALD are visible in Figure $4 a-c$ using HAADF imaging, where they appear as 
bright dots over a darker background corresponding to the graphene support and vacuum. In each image, the $\mathrm{N}$-doped graphene has localized small regions with fewer layers (examples encircled in orange) and folds, resulting in intensity variations in the support material through the mass-contrast contribution in the HAADF signal. The graphene and $\mathrm{N}$ doping production method consistently yields multilayered, and folded sheets, as determined through HRTEM (Figure 1c). Due to the multilayered nature of the N-doped FLG and sheet misorientations observed from the computed diffractogram (Figure 1d), the graphene lattice cannot be resolved using the experimental conditions for our HAADF imaging. Similarly the exact location of the $\mathrm{Pt}$ atoms with respect to the graphene hexagonal lattice and the $\mathrm{N}$-dopants, as done previously by other researchers with other elements on single layer graphene cannot be retrieved..$^{35,52,53}$ However, through quantitative analysis of the HAADF signals in our images (see Experimental Section), we can retrieve the location of the edges (yellow lines) composing the N-doped FLG and Pt atom and cluster locations (pink dots) (Figure $4 \mathrm{~d}-\mathrm{f}$ ). From this analysis, it is clear that the $\mathrm{Pt}$ atoms are primarily located along the edges of the graphene stacked nanosheets with few Pt atoms situated in the central part of the sheets (indicated by green arrows). Remarkably, in each set of ALD cycles (50, 100, and 150), Pt atoms and few-atom clusters are observed on the $\mathrm{N}$-doped graphene support rather than nanoparticles. According to Sun et al., ${ }^{25}$ increased ALD cycling results in increased Pt loading, and the formation and growth of nanoparticles on pure graphene nanosheets. Instead, our work shows that the growth of nanoparticles did not occur within the $\mathrm{N}$-doped graphene samples, as the atoms and clusters appear to be stabilized, and thus rendered immobile by the defects within the graphene lattice and the N-dopants. Also, a decreased nominal Pt loading in comparison to the graphene nanosheets reported by Sun et al. $^{25}$ may be responsible for the lack of nanoparticles in the Ndoped samples. Furthermore, our measurements show that the specific Pt density in the $\mathrm{N}$-doped samples varied among locations on the graphene sheets, likely due to local variations in defects in the graphene lattice, $\mathrm{N}$-dopant concentration, dopant site distribution, and variations in $\mathrm{Pt}$ loading. It is expected, as suggested by Hsueh et al., ${ }^{11}$ that increasing the number of ALD cycles and therefore the Pt loading, would eventually form nanoparticles as the $\mathrm{N}$-dopant and edge nucleation sites are filled by Pt atoms, but this is not observed up to the $150 \mathrm{ALD}$ cycles in our work

HRTEM, using negative $\mathrm{C}_{\mathrm{s}}$ imaging conditions (Figure 5), can be used to provide complementary information to the HAADF images in Figure 4. The Pt atoms are observed as sharp dots in the HRTEM images ${ }^{54,55}$ and the amorphous $C$ contamination is encircled in blue, where the contrast of the image is dependent on the microscope imaging parameters. However, the unambiguous identification of $\mathrm{Pt}$ atoms and clusters is difficult in the HRTEM images, due to the multiplelayered nature of the graphene. To more precisely observe the location of the $\mathrm{Pt}$ with respect to local graphene defects and $\mathrm{N}$ dopants, experiments with single sheet graphene would need to be conducted. Further, the presence of Pt on the N-doped FLG is confirmed with EDXS (Figure S3). Small Pt peaks are present in the EDX spectrum of the sample (Figure S3), while no such peaks are observed in the reference spectrum acquired over vacuum. The $\mathrm{Cu}$, and $\mathrm{C}$ in the reference spectrum are due to the lacey $\mathrm{C}$ support on the $\mathrm{Cu}$ TEM grid, while the Mo and $\mathrm{Mn}$ are likely originating from the sample holder, apertures, and
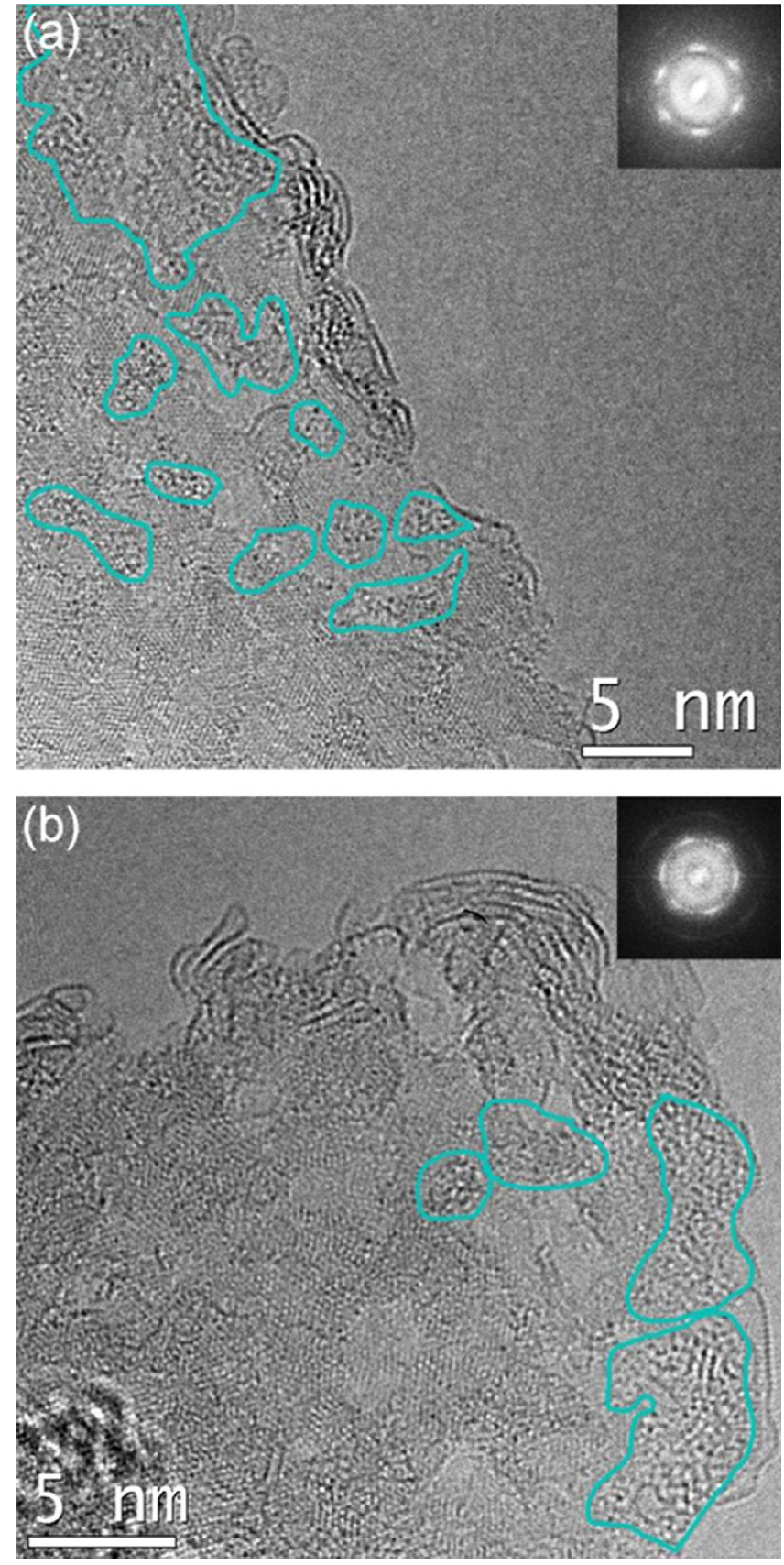

Figure 5. HRTEM image of N-doped graphene with 50 ALD Pt cycles at two separate locations ( $\mathrm{a}$ and $\mathrm{b}$ ) ( $\mathrm{Cs}=-15 \mu \mathrm{m}$ for each image). The amorphous $\mathrm{C}$ contamination is encircled in blue. The Pt atoms and clusters can be identified as sharp dots; however, the multilayered nature of the samples makes the precise location of $\mathrm{Pt}$ ambiguous. The top insets of $a$ and $b$ show the Fourier transform diffractograms to illustrate the characteristic hexagonal structure of the $\mathrm{N}$-doped graphene.

instrumental contributions. The spectrum from the $\mathrm{N}$-doped FLG and the comparison of the in-vacuum spectrum confirm that the $\mathrm{Pt}$ signal is arising from the sample rather than instrumental effects or contamination. Further, the $\mathrm{O}$ in both the reference and sample spectra is related to an incomplete reduction of the GO.

We can now discuss the relationship between the $\mathrm{Pt}$ observation and the detection of $\mathrm{N}$ in different bonding configurations. Through various calculations ${ }^{15,20}$ in literature, it 
has been shown that $\mathrm{Pt}$ is expected to bind to the $\mathrm{C}$ atoms adjacent to $\mathrm{N}$-dopants due to the imposed positive charge. Holmes et al. ${ }^{15}$ showed, in fact, that $\mathrm{N}$ incorporation increases $\mathrm{Pt}$ nucleation and that $\mathrm{Pt}$ ripening is unfavorable over pyridinic sites. This creates an ideal situation for Pt catalyst deposition as it results in an increased Pt loading without Pt agglomeration, as shown in Figures 4 and 5 through the production of $\mathrm{Pt}$ atoms and clusters. The predominant location of $\mathrm{Pt}$ at $\mathrm{N}$-doped graphene edges (Figure 4) and the lack of Pt ripening is consistent with calculations, ${ }^{9}$ suggesting that the adsorption energy of $\mathrm{Pt}$ on graphene is enhanced at edge locations due to dangling bonds and the presence of pyridinic-type dopants at the FLG edge, thus allowing for the stable formation of atoms and clusters. Additionally, Kong et al. ${ }^{9}$ calculated that the diffusion rate of $\mathrm{Pt}$ on the surface of graphene is greater than the diffusion at edge sites, which is consistent with the experimental data found here with the location of $\mathrm{Pt}$ on graphene edges. An additional contribution to the observation is due to Groves et al. ${ }^{56}$ who concluded that $\mathrm{N}$-doping enhances the adsorption energy of $\mathrm{Pt}$ on $\mathrm{C}$. Thus, the presence of $\mathrm{Pt}$ atoms and clusters located on the terraces of the graphene nanosheets (labeled with green arrows in Figure 4) and not as $\mathrm{Pt}$ nanoparticles, is likely linked to $\mathrm{N}$-dopants increasing the $\mathrm{Pt}-\mathrm{C}$ bond energy or to vacancies in the graphene lattice. ${ }^{15}$ This possibly suggests that the $\mathrm{Pt}$ remains in atomic and atomic-cluster form on the $\mathrm{N}$-doped graphene due to the incorporation of vacancies and edge defects, and the increased binding energy between $\mathrm{Pt}$ and $\mathrm{C}$ from $\mathrm{N}$-dopants, therefore reducing the mobility of $\mathrm{Pt}$ on the surface of the FLG and preventing the growth into larger nanoparticles. The EEL spectra in Figure 3 indicate that pyridinic-N (peak P1) is contained in each examined graphene nanosheet, which can influence the preferential position of $\mathrm{Pt}$ atoms and clusters at the edge of these sheets. According to calculations performed by Holmes et al., ${ }^{15} \mathrm{Pt}$ nucleation is more favorable on pyridinictype dopants rather than graphitic-type, while Pt ripening is unfavorable on pyridinic-type in comparison to graphitic-type. The schematic in Figure 6 illustrates the bonding configuration

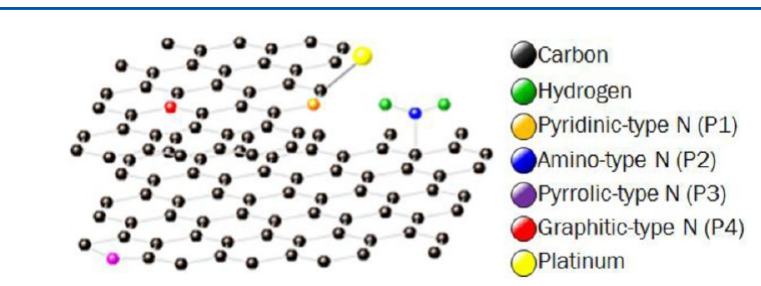

Figure 6. Schematic diagram of $\mathrm{Pt}$ atom located at an edge site bonded to the $\mathrm{C}$ atoms adjacent to a pyridinic-dopant. The probable $\mathrm{Pt}-\mathrm{C}$ bonding is highlighted in this image when considering the $\mathrm{N}$-dopants in the graphene lattice from the enhanced nucleation energy on pyridinic-type dopants.

of the stabilized Pt atoms at the edge location adjacent to the pyridinic-type dopant. The favored nucleation on pyridinic-type over graphitic-type dopants increases the probability of $\mathrm{Pt}$ atoms chemisorbing to edge locations, thus adopting the configuration shown in Figure 6. Our study agrees with these calculations, ${ }^{15}$ as the EEL spectra in Figure 3 indicate that both pyridinic (P1)- and graphitic (P4)-type dopants moderate the effect of both ripening and nucleation in the sample. However, it is clear from Figure 4 that $\mathrm{Pt}$ prefers to nucleate at edge sites, thus resulting in the formation of atoms and clusters at edges rather than a continued growth to nanoparticles from the increased binding energy of available dangling bonds and the decreased ripening from $\mathrm{N}$-dopants.

We now discuss the role of $\mathrm{N}$-dopant sites on the ALD growth mechanism. The literature on $\mathrm{C}$ nanotubes indicates that a substrate-enhanced growth rate of ALD Pt occurs when defects are introduced by oxygen plasma treatment. ${ }^{11}$ That work showed that $\mathrm{Pt}$ atoms initially attach at defect sites and linearly grow into nanoparticles with subsequent ALD cycles once the defect sites are filled. ${ }^{11}$ This suggests that preferential formation of $\mathrm{Pt}$ atoms and clusters can be controlled through the number of successive ALD cycles, where Pt atoms and clusters will form when nucleation sites remain available by ensuring the $\mathrm{Pt}$ atomic density does not exceed the lattice defect density. The literature discussed here and the results shown in Figure 4 suggest that, in order to ensure that Pt atoms and clusters are consistently formed, both defective $\mathrm{N}$-doped graphene and ALD are required to increase the binding energy from dangling bonds at defect sites and $\mathrm{N}$-dopants, and to control the Pt density with deposition cycles, respectively. Because the $\mathrm{N}$-dopant species and overall $\mathrm{N}$ concentration are not consistent between and among graphene nanosheets as shown here, the Pt distribution is varied. Unfortunately, more ALD cycles could result in low $\mathrm{N}$ concentration graphene nanosheets containing Pt nanoparticles, while other areas with high $\mathrm{N}$ concentration would still maintain atoms and clusters. In an effort to homogenize the Pt distribution, and potentially the Pt size (assuming more ALD cycles are performed) and specific activity, the $\mathrm{N}$-dopant distribution and concentration must be made consistent.

Overall, our results have important implications for the steps involved in the operation of the PEMFC. During ORR, it is desirable to increase the number of active sites by enhancing the surface area to volume ratio of the $\mathrm{Pt}$ particles, and to prevent Pt agglomeration with time. Calculations ${ }^{26,27}$ have been completed to examine the efficiency of $\mathrm{Pt}$ atoms and clusters as catalysts for the PEMFC; however, the inability to deposit single atoms without the formation of nanoparticles has limited experimental measurements. The observations in the study presented here demonstrate that the development of stable $\mathrm{Pt}$ atoms and clusters in the absence of nanoparticles has been realized. Thus our work paves the way to examine the efficiency of $\mathrm{Pt}$ atoms and clusters as catalysts for the PEMFC. Through the combination of the characterization techniques and material preparation methods presented in this work, the efficiency of the ORR can be better understood and then optimized. Work is currently in progress to systematically assess the catalytic properties of the well controlled samples.

\section{CONCLUSIONS}

In summary, we have presented a detailed chemical and structural investigation of $\mathrm{N}$-doped FLG graphene derived from GO on which Pt was deposited by ALD. From HRTEM and computed diffractograms, we have shown that the short-range hexagonal characteristic lattice of graphene was largely preserved after N-doping, but a high density of disorder was present. Detailed high-resolution spectroscopic analysis through ELNES of the C-K edge showed that the nature of the graphene $\mathrm{sp}^{2}$ hybridization, consistent with strong $\pi^{*}$ and $\sigma^{*}$ peaks, was maintained after $\mathrm{N}$-doping. We were able to probe the dopant-site locations of the $\mathrm{N}$-species through detailed analysis of the $\mathrm{N}-\mathrm{K}$ edge, which showed strong features consistent with pyridinic, amino, and graphitic sites. Based on the literature that we have discussed, the features 
present in the near edge structures promote an increase in the $\mathrm{Pt}-\mathrm{C}$ binding energy. We have demonstrated that the dopant concentration varies among and within the graphene sheets and that local probing techniques, rather than bulk average methods, must be used to assess the effectiveness of the doping process. Most importantly, the effects of the reduced $\mathrm{Pt}$ particle size achieved through ALD and the prevention of the $\mathrm{Pt}$ agglomeration from $\mathrm{N}$-doping and dangling bonds were apparent through HAADF and HRTEM imaging, where only single $\mathrm{Pt}$ atoms and atomic clusters were observed. These are sustained primarily at graphene edges with few atoms and clusters stable on terrace sites. This effect was maintained up to 150 ALD cycles without the formation of nanoparticles. We have therefore shown that $\mathrm{N}$-doped graphene, in combination with ALD, provides a controlled means to produce single atoms and atomic clusters of $\mathrm{Pt}$. The techniques presented here pave the way to fine-tune the specific $\mathrm{N}$-dopant selection and the $\mathrm{Pt}$ size in order to ultimately address the current issues limiting the mass-production of the PEMFC.

\section{ASSOCIATED CONTENT}

\section{S Supporting Information}

Figures of (i) a $\mathrm{N}$-doped graphene nanoprobe diffraction pattern, (ii) $\mathrm{C}-\mathrm{K}, \mathrm{N}-\mathrm{K}$, and $\mathrm{O}-\mathrm{K}$ edges on a relative energy scale, and (iii) sample and reference EDX spectra from $\mathrm{N}$ doped graphene with 50 ALD cycles. This material is available free of charge via the Internet at http://pubs.acs.org.

\section{AUTHOR INFORMATION}

\section{Corresponding Author}

*E-mail: gbotton@mcmaster.ca; Phone: 1 (905) 525-9140 ex. 24767.

\section{Present Addresses}

${ }^{\S}$ Institute of Solid State Research, IFW Dresden, 01171 Dresden, Germany.

"EMAT, University of Antwerp, Groenenborgerlaan 171, B2020 Antwerpen, Belgium.

${ }^{\perp}$ Energy Materials Telecommunications Research Centre, Institut National de la Recherche Scientifique, 1650 Lionel Boulet Boulevard, Varennes, Quebec, J3X 1S2, Canada

\section{Author Contributions}

The manuscript was written through contributions of all authors. Samantha Stambula*, Nicolas Gauquelin,** Matthieu Bugnet,*** Sandeep Gorantla, ${ }^{\dagger}$ and Stuart Turner ${ }^{\ddagger}$ performed HAADF imaging,,$* *$ EELS acquisition, $*, * * *$ nanoprobe diffraction, $*, \dagger$ HRTEM imaging, $* *$ and image processing*. Shuhui Sun, ${ }^{\dagger *}$, Jian Liu, ${ }^{\dagger *}$ and Gaixia Zhang ${ }^{\dagger * *}$ performed the sample preparation, including the graphene synthesis, ${ }^{\dagger *}, \dagger * * \mathrm{~N}$ doping, ${ }^{\dagger *, \dagger * *}$ and Pt $\mathrm{ALD}^{\dagger *,+*, \dagger * *}$. Xueliang $\mathrm{Sun}^{\dagger \dagger}$ and Gianluigi A. Botton planned, designed, and guided experiments for the sample preparation ${ }^{\dagger \dagger}$ and microscopy $y^{+1}$. All authors have given approval to the final version of the manuscript.

\section{Notes}

The authors declare no competing financial interest.

\section{ACKNOWLEDGMENTS}

This work is supported by NSERC and Ballard Power Systems Incorporated via a strategic grant to the University of Western Ontario and McMaster University and partially through the NSERC-APC network CaRPE-FC. The electron microscopy presented here was completed at the Canadian Center for
Electron Microscopy, a facility supported by NSERC and McMaster University. Further, S.T. gratefully acknowledges the Fund for Scientific Research Flanders (FWO) for a postdoctoral fellowship. The graphene EEL spectrum was acquired by David Rossouw using commercial graphene obtained from Graphene Supermarket. EDX spectroscopy analysis was carried out at CANMET Materials Technology Laboratory, a facility supported by Natural Resources Canada. EDX spectra were acquired by Feihong Nan from N-doped graphene with ALD Pt. Samples were supplied by the University of Western Ontario with preliminary characterization and sample preparation advice provided by Ruiying $\mathrm{Li}$. Lastly, we would like to acknowledge Joerg Jinschek for advice on HRTEM imaging conditions. The coding utilized for HAADF analysis and Pt location was written with the help of Andrew Scullion using MATLAB. Coding for Pt filled circles was completed using a publically available code by Sadik Hava produced in 2010, which makes use of a code from Zhenhai Wang generated in 2002. These codes are available through MATLAB's online forum, MATLAB central file exchange at http://www.mathworks.com/matlabcentral/fileexchange/ 27703-draw-a-filled-circle/content/filledCircle.m.

\section{REFERENCES}

(1) Mehta, V.; Cooper, J. S. Review and Analysis of PEM Fuel Cell Design and Manufacturing. J. Power. Sources 2003, 114, 32-53.

(2) Barbir, F.; Gomez, T. Efficiency and Economics of Proton Exchange Membrane (PEM) Fuel Cells. Int. J. Hydrogen Energy 1997, 22, 1027-1037.

(3) Hammer, B.; Norskov, J. . Theoretical Surface Science and Catalysis - Calculations and Concepts. Adv. Catal. 2000, 45, 71-129.

(4) Gasteiger, H. A.; Kocha, S. S.; Sompalli, B.; Wagner, F. T. Activity Benchmarks and Requirements for Pt, Pt-Alloy, and Non-Pt Oxygen Reduction Catalysts for PEMFCs. Appl. Catal. B: Environ. 2005, 56, 9-35.

(5) Shao, Y.; Yin, G.; Gao, Y. Understanding and Approaches for the Durability Issues of Pt-Based Catalysts for PEM Fuel Cell. J. Power Sources 2007, 171, 558-566.

(6) Lee, K.; Zhang, J.; Wang, H.; Wilkinson, D. P. Progress in the Synthesis of Carbon Nanotube- and Nanofiber-Supported Pt Electrocatalysts for PEM Fuel Cell Catalysis. J. Appl. Electrochem. 2006, 36, 507-522.

(7) Geim, A. K.; Novoselov, K. S. The Rise of Graphene. Nat. Mater. 2007, 6, 183-191.

(8) Lee, C.; Wei, X.; Kysar, J. W.; Hone, J. Measurement of the Elastic Properties and Intrinsic Strength of Monolayer Graphene. Science 2008, 321, 385-388.

(9) Kong, K.; Choi, Y.; Ryu, B.-H.; Lee, J.-O.; Chang, H. Investigation of Metal/Carbon-Related Materials for Fuel Cell Applications by Electronic Structure Calculations. Mater. Sci. Eng., C 2006, 26, 1207-1210.

(10) Li, Y.; Gao, W.; Ci, L.; Wang, C.; Ajayan, P. M. Catalytic Performance of Pt Nanoparticles on Reduced Graphene Oxide for Methanol Electro-Oxidation. Carbon 2010, 48, 1124-1130.

(11) Hsueh, Y.-C.; Wang, C.-C.; Liu, C.; Kei, C.-C.; Perng, T.-P. Deposition of Platinum on Oxygen Plasma Treated Carbon Nanotubes by Atomic Layer Deposition. Nanotechnology 2012, 23, 405603-1-405603-6.

(12) Zhang, L.-S.; Liang, X.-Q.; Song, W.-G.; Wu, Z.-Y. Identification of the Nitrogen Species on N-Doped Graphene Layers and Pt/NG Composite Catalyst for Direct Methanol Fuel Cell. Phys. Chem. Chem. Phys. 2010, 12, 12055-12059.

(13) Wei, D.; Liu, Y.; Wang, Y.; Zhang, H.; Huang, L.; Yu, G. Synthesis of N-Doped Graphene by Chemical Vapor Deposition and Its Electrical Properties. Nano Lett. 2009, 9, 1752-1758.

(14) Sheng, Z.-H.; Shao, L.; Chen, J.-J.; Bao, W.-J.; Wang, F.-B.; Xia, X.-H. Catalyst-Free Synthesis of Nitrogen-Doped Graphene via 
Thermal Annealing Graphite Oxide with Melamine and Its Excellent Electrocatalysis. ACS Nano 2011, 5, 4350-4358.

(15) Holme, T.; Zhou, Y.; Pasquarelli, R.; O’Hayre, R. First Principles Study of Doped Carbon Supports for Enhanced Platinum Catalysts. Phys. Chem. Chem. Phys. 2010, 12, 9461-9468.

(16) Wang, P.; Wang, Z.; Jia, L.; Xiao, Z. Origin of the Catalytic Activity of Graphite Nitride for the Electrochemical Reduction of Oxygen: Geometric Factors vs. Electronic Factors. Phys. Chem. Chem. Phys. 2009, 11, 2730-2740.

(17) Alexeyeva, N.; Shulga, E.; Kisand, V.; Kink, I.; Tammeveski, K. Electroreduction of Oxygen on Nitrogen-Doped Carbon Nanotube Modified Glassy Carbon Electrodes in Acid and Alkaline Solutions. J. Electroanal. Chem. 2010, 648, 169-175.

(18) Bai, J.; Zhu, Q.; Lv, Z.; Dong, H.; Yu, J.; Dong, L. NitrogenDoped Graphene as Catalysts and Catalyst Supports for Oxygen Reduction in Both Acidic and Alkaline Solutions. Int. J. Hydrogen Energy 2013, 38, 1413-1418.

(19) Kim, H.; Lee, K.; Woo, S. I.; Jung, Y. On the Mechanism of Enhanced Oxygen Reduction Reaction in Nitrogen-Doped Graphene Nanoribbons. Phys. Chem. Chem. Phys. 2011, 13, 17505-17510.

(20) Zhang, L.; Niu, J.; Dai, L.; Xia, Z. Effect of Microstructure of Nitrogen-Doped Graphene on Oxygen Reduction Activity in Fuel Cells. Langmuir 2012, 28, 7542-7550.

(21) Ni, S.; Li, Z.; Yang, J. Oxygen Molecule Dissociation on Carbon Nanostructures with Different Types of Nitrogen Doping. Nanoscale 2012, 4, 1184-1189.

(22) Zhou, Y.; Neyerlin, K.; Olson, T. S.; Pylypenko, S.; Bult, J.; Dinh, H. N.; Gennett, T.; Shao, Z.; O’Hayre, R. Enhancement of Pt and $\mathrm{Pt}-$ Alloy Fuel Cell Catalyst Activity and Durability via NitrogenModified Carbon Supports. Energ. Environ. Sci. 2010, 3, 1437-1446.

(23) Li, J.; Liang, X.; King, D. M.; Jiang, Y.-B.; Weimer, A. W. Highly Dispersed Pt Nanoparticle Catalyst Prepared by Atomic Layer Deposition. Appl. Catal. B: Environ. 2010, 97, 220-226.

(24) Liu, C.; Wang, C.-C.; Kei, C.-C.; Hsueh, Y.-C.; Perng, T.-P. Atomic Layer Deposition of Platinum Nanoparticles on Carbon Nanotubes for Application in Proton-Exchange Membrane Fuel Cells. Small 2009, 5, 1535-1538.

(25) Sun, S.; Zhang, G.; Gauquelin, N.; Chen, N.; Zhou, J.; Yang, S.; Chen, W.; Meng, X.; Geng, D.; Banis, M. N.; et al. Single-Atom Catalysis Using Pt/Graphene Achieved Through Atomic Layer Deposition. Sci. Rep. 2013, 3, 1-9.

(26) Toyoda, E.; Jinnouchi, R.; Hatanaka, T.; Morimoto, Y.; Mitsuhara, K.; Visikovskiy, A.; Kido, Y. The d-Band Structure of Pt Nanoclusters Correlated with the Catalytic Activity for an Oxygen Reduction Reaction. J. Phys. Chem. C 2011, 115, 21236-21240.

(27) Zhou, C.; Wu, J.; Nie, A.; Forrey, R. C.; Tachibana, A.; Cheng, $\mathrm{H}$. On the Sequential Hydrogen Dissociative Chemisorption on Small Platinum Clusters: A Density Functional Theory Study. J. Phys. Chem. C 2007, 111, 12773-12778.

(28) Hummers, W. S.; Offeman, R. E. Preparation of Graphitic Oxide. J. Am. Chem. Soc. 1958, 80, 1339-1339.

(29) Geng, D.; Yang, S.; Zhang, Y.; Yang, J.; Liu, J.; Li, R.; Sham, T.K.; Sun, X.; Ye, S.; Knights, S. Nitrogen Doping Effects on the Structure of Graphene. Appl. Surf. Sci. 2011, 257, 9193-9198.

(30) Li, X.; Wang, H.; Robinson, J. T.; Sanchez, H.; Diankov, G.; Dai, H. Simultaneous Nitrogen Doping and Reduction of Graphene Oxide. J. Am. Chem. Soc. 2009, 131, 15939-15944.

(31) Graphene Supermarket, Graphene Transmission Electron Microscopy Support Films, http://www.graphene-supermarket.com/ images/XC/TEM/GrapheneTEMgrids-Generalinfo.pdf (accessed Feb 18, 2013).

(32) Zobelli, A.; Gloter, A.; Ewels, C. P.; Seifert, G.; Colliex, C. Electron Knock-On Cross Section of Carbon and Boron Nitride Nanotubes. Phys. Rev. B 2007, 75, 245402-1-245402-9.

(33) Meyer, J. C.; Eder, F.; Kurasch, S.; Skakalova, V.; Kotakoski, J.; Park, H. J.; Roth, S.; Chuvilin, A.; Eyhusen, S.; Benner, G.; et al. Accurate Measurement of Electron Beam Induced Displacement Cross Sections for Single-Layer Graphene. Phys. Rev. Lett. 2012, 108, 196102-1-196102-6.
(34) Jinschek, J. R.; Yucelen, E.; Calderon, H. A.; Freitag, B. Quantitative Atomic 3-D Imaging of Single/Double Sheet Graphene Structure. Carbon 2011, 49, 556-562.

(35) Nicholls, R. J.; Murdock, A. T.; Tsang, J.; Britton, J.; Pennycook, T. J.; Koos, A.; Nellist, P. D.; Grobert, N.; Yates, J. R. Probing the Bonding in Nitrogen-Doped Graphene Using Electron Energy Loss Spectroscopy. ACS Nano 2013, 7, 7145-7150.

(36) Egerton, R. F. Electron Energy-Loss Spectroscopy in the Electron Microscope; Springer: Boston, MA, 2011.

(37) Warner, J. H.; Rümmeli, M. H.; Ge, L.; Gemming, T.; Montanari, B.; Harrison, N. M.; Büchner, B.; Briggs, G. A. D. Structural Transformations in Graphene Studied with High Spatial and Temporal Resolution. Nat. Nanotechnol. 2009, 4, 500-504.

(38) Gómez-Navarro, C.; Meyer, J. C.; Sundaram, R. S.; Chuvilin, A.; Kurasch, S.; Burghard, M.; Kern, K.; Kaiser, U. Atomic Structure of Reduced Graphene Oxide. Nano Lett. 2010, 10, 1144-1148.

(39) Meyer, J. C.; Kisielowski, C.; Erni, R.; Rossell, M. D.; Crommie, M. F.; Zettl, A. Direct Imaging of Lattice Atoms and Topological Defects in Graphene Membranes. Nano Lett. 2008, 8, 3582-3586.

(40) Meyer, J. C.; Kurasch, S.; Park, H. J.; Skakalova, V.; Künzel, D.; GroB, A.; Chuvilin, A.; Algara-Siller, G.; Roth, S.; Iwasaki, T.; et al. Experimental Analysis of Charge Redistribution due to Chemical Bonding by High-Resolution Transmission Electron Microscopy. Nat. Mater. 2011, 10, 209-215.

(41) Huang, P. Y.; Ruiz-Vargas, C. S.; Van der Zande, A. M.; Whitney, W. S.; Levendorf, M. P.; Kevek, J. W.; Garg, S.; Alden, J. S.; Hustedt, C. J.; Zhu, Y.; et al. Grains and Grain Boundaries in SingleLayer Graphene Atomic Patchwork Quilts. Nature 2011, 469, 389393.

(42) Kim, K.; Lee, Z.; Regan, W.; Kisielowski, C.; Crommie, M. F.; Zettl, A. Grain Boundary Mapping in Polycrystalline Graphene. ACS Nano 2011, 5, 2142-2146.

(43) Luo, D.; Zhang, G.; Liu, J.; Sun, X. Evaluation Criteria for Reduced Graphene Oxide. J. Phys. Chem. C 2011, 115, 11327-11335.

(44) Xu, Z.; Bando, Y.; Liu, L.; Wang, W.; Bai, X.; Golberg, D. Electrical Conductivity, Chemistry, and Bonding Alternations Under Graphene Oxide to Graphene Transition as Revealed by In Situ TEM. ACS Nano 2011, 5, 4401-4406.

(45) Jeong, H.-K.; Noh, H.-J.; Kim, J.-Y.; Jin, M. H.; Park, C. Y.; Lee, Y. H. X-ray Absorption Spectroscopy of Graphite Oxide. Europhys. Lett. 2008, 82, 67004-1-67004-5.

(46) Ganguly, A.; Sharma, S.; Papakonstantinou, P.; Hamilton, J. Probing the Thermal Deoxygenation of Graphene Oxide Using HighResolution In Situ X-ray-Based Spectroscopies. J. Phys. Chem. C 2011, 115, 17009-17019.

(47) Shimoyama, I.; Wu, G.; Sekiguchi, T.; Baba, Y. Evidence for the Existence of Nitrogen-Substituted Graphite Structure by Polarization Dependence of Near-Edge X-ray-Absorption Fine Structure. Phys. Rev. B: Condens. Matter Mater. Phys. 2000, 62, 6053-6056.

(48) Zhong, J.; Deng, J.-J.; Mao, B.-H.; Xie, T.; Sun, X.-H.; Mou, Z.G.; Hong, C.-H.; Yang, P.; Wang, S.-D. Probing Solid State N-Doping in Graphene by X-ray Absorption Near-Edge Structure Spectroscopy. Carbon 2012, 50, 335-338.

(49) Abbas, G.; Papakonstantinou, P.; Iyer, G. R. S.; Kirkman, I. W.; Chen, L. Substitutional Nitrogen Incorporation Through RF Glow Discharge Treatment and Subsequent Oxygen Uptake on Vertically Aligned Carbon Nanotubes. Phys. Rev. B 2007, 75, 195429-1195429-9.

(50) Van Khai, T.; Na, H. G.; Kwak, D. S.; Kwon, Y. J.; Ham, H.; Shim, K. B.; Kim, H. W. Significant Enhancement of Blue Emission and Electrical Conductivity of N-Doped Graphene. J. Mater. Chem. 2012, 22, 17992-18003.

(51) Casanovas, J.; Ricart, J. M.; Rubio, J.; Illas, F.; Jimenez-Mateos, J. $\mathrm{M}$. Origin of the Large N 1s Binding Energy in X-ray Photoelectron Spectra of Calcined Carbonaceous Materials. J. Am. Chem. Soc. 1996, 118, 8071-8076.

(52) Zan, R.; Bangert, U.; Ramasse, Q.; Novoselov, K. S. MetalGraphene Interaction Studied via Atomic Resolution Scanning Transmission Electron Microscopy. Nano Lett. 2011, 11, 1087-1092. 
(53) Zhou, W.; Kapetanakis, M. D.; Prange, M. P.; Pantelides, S. T.; Pennycook, S. J.; Idrobo, J.-C. Direct Determination of the Chemical Bonding of Individual Impurities in Graphene. Phys. Rev. Lett. 2012, 109, 206803-1-206803-5.

(54) Cretu, O.; Krasheninnikov, A. V.; Rodríguez-Manzo, J. A.; Sun, L.; Nieminen, R. M.; Banhart, F. Migration and Localization of Metal Atoms on Strained Graphene. Phys. Rev. Lett. 2010, 105, 196102-1196102-4.

(55) Gan, Y.; Sun, L.; Banhart, F. One- and Two-Dimensional Diffusion of Metal Atoms in Graphene. Small 2008, 4, 587-591.

(56) Groves, M. N.; Malardier-Jugroot, C.; Jugroot, M. Improving Platinum Catalyst Durability with a Doped Graphene Support. J. Phys. Chem. C 2012, 116, 10548-10556. 